\title{
A design of selective solar absorber for high temperature applications
}

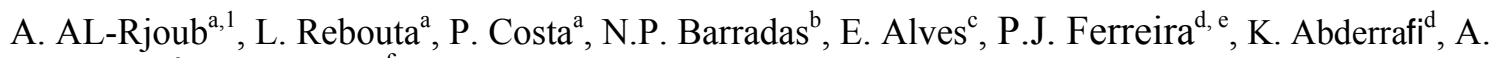 \\ Matilainen $^{\mathrm{f}}$, K. Pischow ${ }^{\mathrm{f}}$ \\ a Centre of Physics, University of Minho, Campus de Azurém, 4800-058 Guimarães, Portugal \\ b Centro de Ciências e Tecnologias Nucleares, Instituto Superior Técnico, EN 10, km 139.7, 2695-066 Bobadela \\ LRS, Portugal \\ c Campus Tecnológico e Nuclear, Instituto Superior Técnico, EN 10, km 139.7, 2695-066 Bobadela LRS, Portugal \\ d International Iberian Nanotechnology Laboratory, Av. Mestre José Veiga s/n, 4715-330 Braga, Portugal \\ e Materials Science and Engineering Program, The University of Texas at Austin, Austin, USA \\ f Savo Solar Oy, Insinöörinkatu 7, 50100 Mikkeli, Finland
}

\begin{abstract}
This study presents a design of multilayer solar selective absorber for high temperature applications. The optical stack of this absorber is composed of four layers deposited by magnetron sputtering on stainless steel substrates. The first is a back-reflector tungsten layer, which is followed by two absorption layers based on $\mathrm{CrAlSiN}_{\mathrm{x}} / \mathrm{CrAlSiO}_{\mathrm{y}} \mathrm{N}_{\mathrm{x}}$ structure for phase interference. The final layer is an antireflection layer of $\mathrm{SiAlO}_{\mathrm{x}}$. The design was theoretically modelled with SCOUT software using transmittance and reflectance curves of individual thin layers, which were deposited on glass substrates. The final design shows simultaneously high solar absorbance $\alpha=95.2 \%$ and low emissivity $\varepsilon=9.8 \%$ (at $400{ }^{\circ} \mathrm{C}$ ) together with high thermal stability at $400{ }^{\circ} \mathrm{C}$, in air, and $600{ }^{\circ} \mathrm{C}$ in vacuum for $650 \mathrm{~h}$.
\end{abstract}

Keywords: solar selective absorber, optical constants, dielectric function, sputtered $\mathrm{CrAlSiN}_{\mathrm{x}}$ $/ \mathrm{CrAlSiO}_{\mathrm{y}} \mathrm{N}_{\mathrm{x}}$

\section{Introduction}

Solar thermal energy is already being used for electricity production by using the concentration solar power (CSP) technology. This technology uses parabolic-trough solar systems that concentrate sunlight up to 80 times onto evacuated receiver tubes. The energy is absorbed at the solar absorption pipe by the coated selective layers. The resulting energy can be subsequently used in steam turbines to produce electricity (Fernández-García et al., 2010)(Odeh et al., 1998)(Ward, 1997). However, comparing with other resources, the relative cost of electricity generated by solar thermal technology is still high. The cost can be reduced by improving the optical and thermal properties of the coating materials, and by increasing the operating temperature more than $450^{\circ} \mathrm{C}$ (Rebouta et al., 2015) and by improvements in the long-term stability. These improvements can be done by an adequate materials selection (Kennedy,

\footnotetext{
${ }^{1}$ Corresponding author - e-mail address: abbasp185@yahoo.com (A. AL-Rjoub)
} 
2002), maintaining the optical performance at higher temperatures and with higher durability. Efficient designs should have high absorbance $(\alpha)$ at solar radiation region (wavelength range of 0.3- $2.0 \mu \mathrm{m}$ ), low thermal emittance in IR region (wavelength range greater $2.0 \mu \mathrm{m}$ ) and long-term resistance against oxidation and barrier diffusion at high temperature.

Most of selective solar absorber coatings are based on metal-dielectric nanocomposite coatings (Cermet), such as $\mathrm{Mo}-\mathrm{Al}_{2} \mathrm{O}_{3}$ (Zhang et al., 2006), $\mathrm{Pt}_{-} \mathrm{Al}_{2} \mathrm{O}_{3}$ (Nuru et al., 2012), WTi- $\mathrm{Al}_{2} \mathrm{O}_{3}$ (Wang et al., 2017) and $\mathrm{AlSiO}_{\mathrm{x}}: \mathrm{W}$ (Dias et al., 2017). With these kinds of material, it is easy to tune the optical properties and the optical constants of the different layers, which can be done by varying the metal volume factor of ceramic layers. As a result, it is possible to optimize the absorptance according to the double interference theory of absorption (Zhang et al., 1992). Moreover, all those absorbers are multilayers coating that consist of IR-reflective metallic base layer such as tungsten or molybdenum, a double interference absorption (high absorber (HA) and low absorber (LA)) layers and a ceramic antireflection (AR) surface layer (Rebouta et al., 2015). However, such coatings have limited durability at higher temperature due to oxidation or diffusion of the metal component in the dielectric matrix, which limits their applications (Selvakumar and Barshilia, 2012).

Other designs are based on layers of metal nitrides and oxynitrides structure, such as TiAlN/TiAlON/Si ${ }_{3} \mathrm{~N}_{4}$ (Barshilia et al., 2007), W/AlSiN/AlSiON/AlSiO y (Rebouta et al., 2015), and AlCrSiN/AlCrSiON/AlCrO (Zou et al., 2016). Those stacks show high oxidation resistance and high thermal stability at high temperatures, because of nitrides and oxynitrides, which show good mechanical, chemical and thermal properties at higher temperature.

This work presents a new design of solar selective absorber for high temperature applications, based on nitrides and oxynitrides with structure $\left(\mathrm{W} / \mathrm{CrAlSiN} \mathrm{x}_{\mathrm{x}} / \mathrm{CrAlSiO}_{\mathrm{y}} \mathrm{N}_{\mathrm{x}} / \mathrm{SiAlO}_{\mathrm{x}}\right)$.

\section{Experimental}

All layers were deposited by dc magnetron sputtering $\left(\mathrm{P}_{\mathrm{Ar}}=0.37 \mathrm{~Pa}\right.$, current density $6.4 \mathrm{~mA} / \mathrm{cm}^{2}$, pulsed bias of $-60 \mathrm{~V}, \mathrm{f}=90 \mathrm{kHz}$, room temperature and base pressure $2 \times 10^{-4} \mathrm{~Pa}$ ), except in tungsten layer case, where the current density was $12.7 \mathrm{~mA} / \mathrm{cm}^{2}$. The stainless steel substrates were ultra sound cleaned in acetone for $15 \mathrm{~min}$, and ion etched prior the deposition. Individual layers of $\mathrm{CrAlSiN}$ and $\mathrm{CrAlSiO}_{\mathrm{y}} \mathrm{N}_{\mathrm{x}}$ were deposited on glass substrates with different nitrogen and oxygen partial pressures for 1 min. Spectrophotometry measurements (Shimadzu PC3100 spectrophotometer), in the wavelength range of $0.25-2.5 \mu \mathrm{m}$, were used to measure the transmittance and the reflectance of those layers, and the reflectance data was corrected according to the $\mathrm{Al}$-reference reflectance curve. Those results were used to calculate the optical constants and thicknesses of designed layers by using SCOUT software (Theiss, 2002). With the data obtained from individual layers, the selective absorber stack was designed, and it 
was deposited on stainless steel substrates. Then, it was annealed in air and vacuum at $400{ }^{\circ} \mathrm{C}$ and $600{ }^{\circ} \mathrm{C}$, respectively.

The normal solar absorptance $\left(\alpha_{s}\right)$ was determined from equation (1) by calculated or experimental spectral reflectance data $\mathrm{R}(\lambda)$ and ASTM AM1.5D solar spectral irradiance, $\operatorname{Is}(\lambda)$, at the wave range of 0.3 $-2.5 \mu \mathrm{m}$ (Bogaerts and Lampert, 1983).

$$
\alpha_{\text {sol }}=\frac{\int_{0.3 \mu m}^{2.5 \mu m} I_{s}(\lambda)[1-R(\lambda)] d \lambda}{\int_{0.3 \mu m}^{2.5 \mu m} I_{s}(\lambda) d \lambda}
$$

On the other hand, A Fourier Transform Infrared (FTIR) spectrophotometer from Agilent Technologies equipped with a gold integrating sphere and a $\mathrm{HgCdTe}$ (MCT) detector was used to measure the spectral reflectance in the infrared wavelength range, 1.6-16.7 $\mu \mathrm{m}$. The normal thermal emittance was calculated as the weighted fraction between emitted radiation and the Planck black body distribution at a specific temperature $\mathrm{T}$, using the spectral blackbody emissive power and the spectral reflectance.

For structural and oxidation resistance studies, glancing incident angle XRD was used for samples before and after annealing, that was performed by employing a Bruker AXS Discover D8 operating with $\mathrm{Cu} \mathrm{K} \alpha$ radiation. The measurements were performed at fixed incidence angle of $\alpha=3^{\circ}$. Scanning electron microscopy (SEM) was performed with a Nano SEM-FEI Nova 200(FEG/SEM) microscope. Energy dispersive X-ray Spectroscopy (EDS) analyzes were performed with the electron beam of the SEM, with an energy of $13.5 \mathrm{keV}$ (EDAX - Pegasus X4M system).

The comparison of chemical composition of stack (as deposited, after air and vacuum annealing) was done by using Rutherford Backscattering (RBS) measurements, which were done at the CTN/IST Van de Graaff accelerator using $2 \mathrm{MeV}^{4} \mathrm{He}^{+}$and $2.3 \mathrm{MeV}^{1} \mathrm{H}^{+}$beams and detectors at $140^{\circ}$ and $165^{\circ}$ to the beam direction. Normal incidence was used in the experiments and the obtained data were analysed with the IBA Data Furnace NDF (Barradas and Jeynes, 2008).

\section{Results and discussion}

\subsection{Optical properties of single layers}

$\mathrm{CrAlSiN}_{\mathrm{x}} / \mathrm{CrAlSiO}_{\mathrm{y}} \mathrm{N}_{\mathrm{x}}$ thin layers were previously studied and their optical properties were reported (Al-Rjoub et al., 2017), a series of individual thin layers based on $\mathrm{CrAlSiN}_{\mathrm{x}} / \mathrm{CrAlSiO}_{\mathrm{y}} \mathrm{N}_{\mathrm{x}}$ were deposited with different nitrogen and oxygen partial pressures as reactive gases. Fig. 1 shows the optical constants, refractive index (n) and extinction coefficient (k), as a function of wavelength in the range of $250-2500$ $\mathrm{nm}$, which were obtained from modeling of the experimental $\mathrm{T}$ and $\mathrm{R}$ spectra. It shows the general 
behavior of $\mathrm{n}$ and $\mathrm{k}$ with a decrease as the gases partial pressures increase for both nitride and oxynitride layers. Moreover, it is seen that the refractive indices for the $\mathrm{CrAlSiN}_{\mathrm{x}}$ layers increase in the wavelength range of $300-1000 \mathrm{~nm}$, which make these layers appropriate materials for selective absorption of solar radiation and other optical applications, because it contributes to the solar absorption enhancing through the interference effect. Refractive indices and thicknesses of the bilayer structure should be chosen in order to obtain destructive interference at wavelengths around $0.5 \mu \mathrm{m}$ and $1.3 \mu \mathrm{m}$, contributing to the decrease of the reflectance of the solar radiation and consequently improving its absorptance. An optical path length (product of the refractive index with the thickness, $n d$ ) of $1 / 4$ wavelength (in a layer) would produce a net shift of $1 / 2$ wavelength between the light reflected from the top surface and from the bottom interface, resulting in cancellation (Yin and Collins, 1995). The increase of refractive index in the wavelength range of $300-1000 \mathrm{~nm}$ allows to have a broad range with high degree of destructive interference effect.

The refractive index of $\mathrm{CrAlSiO}_{y} \mathrm{~N}_{\mathrm{x}}$ layers also shows a similar behavior with wavelength, but for high gases partial pressures it becomes almost constant.

(a)

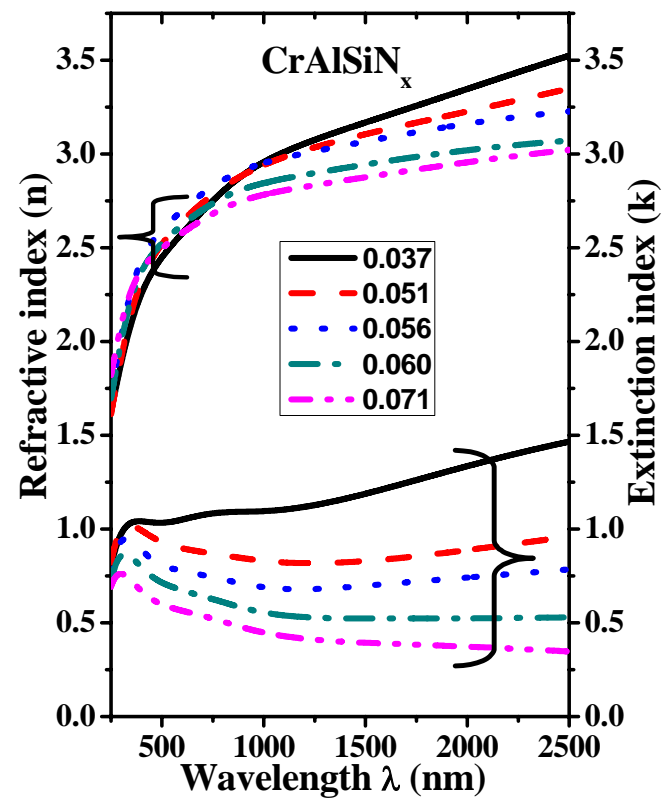

(b)

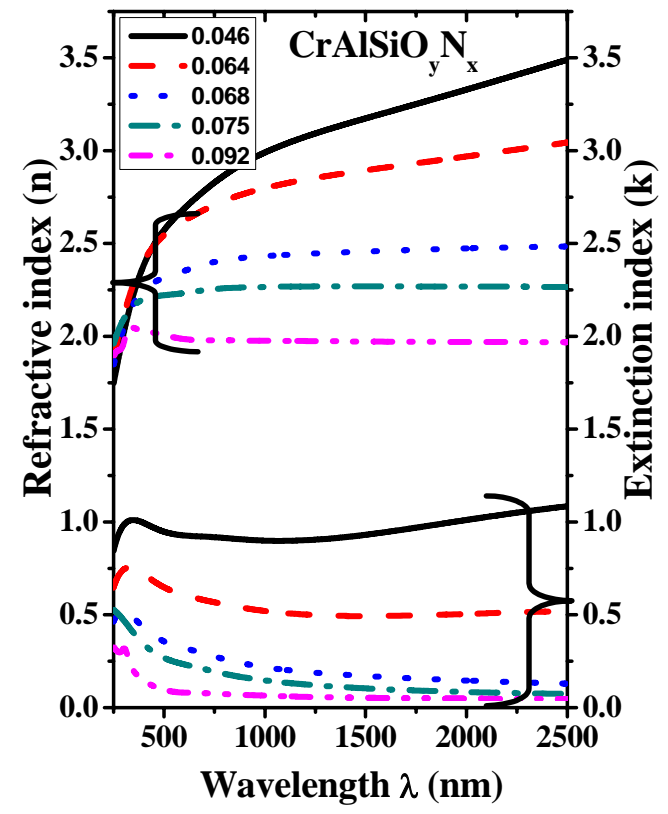

Fig. 1: Refractive index (n) and extinction coefficient (k) as a function of wavelength of: (a) $\mathrm{CrAlSiN}_{\mathrm{x}}$, prepared with increasing nitrogen partial pressure. (b) $\mathrm{CrAlSiO}_{y} \mathrm{~N}_{\mathrm{x}}$ as a function of wavelength, prepared with increasing nitrogen and oxygen partial pressures.

Elemental Tungsten is a good candidate for back-reflector layer in selective thermal absorber tandem, due to its high temperature melting point and due to high reflectance in IR region of radiation $(\mathrm{R} \%=94.6$ 
at $\lambda>2.5 \mu \mathrm{m}$ ) as shown in Fig. 2. High reflectivity of W in IR region decreases the emissivity of stacks. In addition, $\mathrm{W}$ also contributes in energy absorption at solar radiation region, due to its reflectance in visible region (Fig. 2). More information about optical constants ( $\mathrm{n}$ and $\mathrm{k}$ ) as a function of wavelength $(\lambda)$ is shown in Fig. 2.

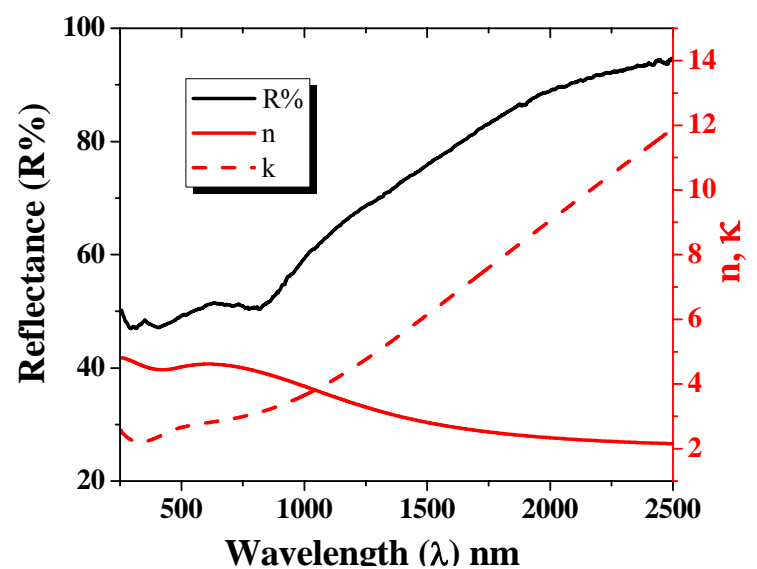

Fig. 2: Reflectance, $\mathrm{n}$ and $\mathrm{k}$ of tungsten deposited on polished stainless steel.

Finally, the antireflection layer $\left(\mathrm{SiAlO}_{\mathrm{x}}\right)$ has a very low extinction coefficient (almost goes to zero) and it has a refractive index around 1.50, as shown in Fig. 3. In accordance to that, this layer is transparent and it is a good candidate for antireflective layer. Moreover, it protects other layers against oxidation.

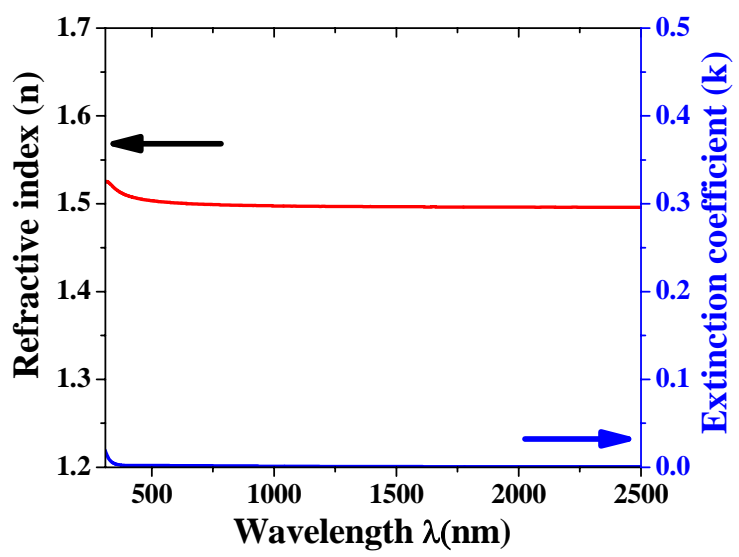

Fig.3: Refractive index (n) and extinction coefficient (қ) of the antireflection layer $\left(\mathrm{SiAlO}_{\mathrm{P}=0.062 \mathrm{~Pa}}\right)$

\subsection{The structure of single layers}

XRD was performed for single layers used in the absorber stack. As shown in Fig. 4, all layers are amorphous except W layer. Despite the W coatings showed a combination of both $\alpha$ - and $\beta$ - phase of growth, the $\alpha$ - phase is the dominant. So, W is polycrystalline with (110) orientation ( $2 \theta=40^{\circ}$ ) (Sibin et 
al., 2015)(Shen and Mai, 2006). Indeed, SEM cross sectional micrographs of thick single layers are completely agreeing with the XRD analysis, as shown in Fig. 5.

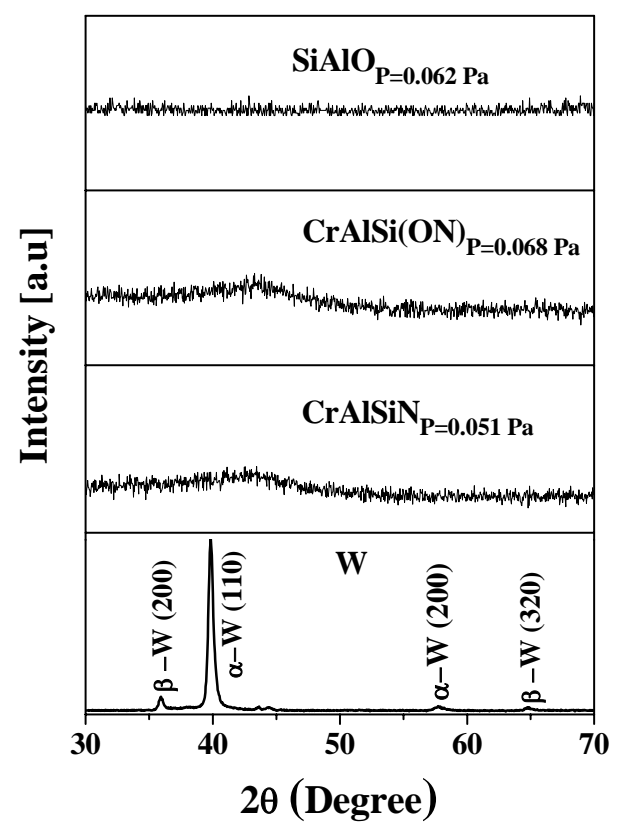

Fig. 4: XRD patterns of single layers performed with fixed incidence angle of $3^{\circ}$ of: $\mathrm{W}$ deposited on stainless steel, CrAlSiN $\mathrm{P}=0.051 \mathrm{~Pa}_{\mathrm{Pa}}, \mathrm{CrAlSi}(\mathrm{ON})_{\mathrm{P}=0.068 \mathrm{~Pa}}$ and $\mathrm{SiAlO}_{\mathrm{P}=0.062 \mathrm{~Pa}}$ layers deposited on silicon substrate.
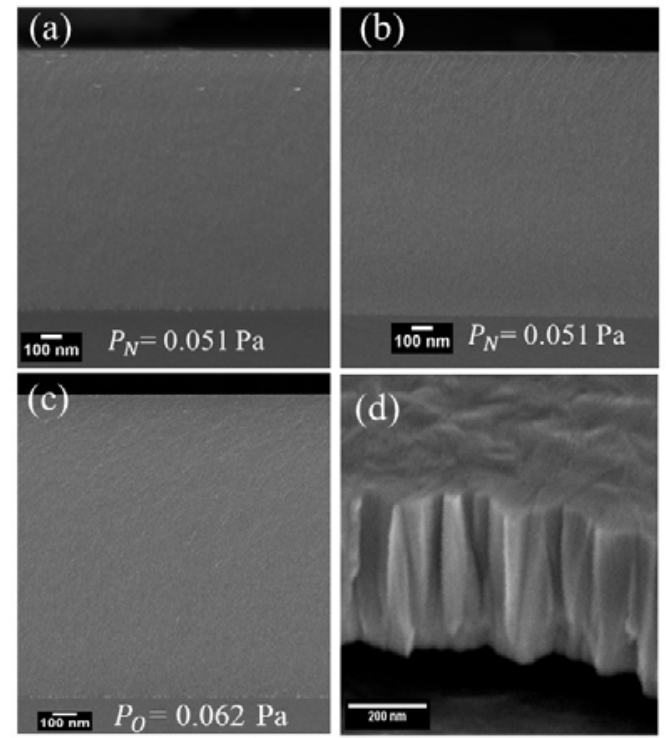

Fig. 5: Cross-sectional SEM micrographs of (a) $\mathrm{CrAlSiN}_{\mathrm{P}=0.051 \mathrm{~Pa}}$, (b) $\mathrm{CrAlSiON}_{\mathrm{P}=0.068 \mathrm{~Pa}}$, (c) $\mathrm{SiAlO}_{\mathrm{P}=0.062 \mathrm{~Pa}}$ and (d) Tungsten (W) as thick single layers. 


\subsection{Design of the multilayer}

The design was theoretically modelled with SCOUT software using transmittance and reflectance curves of individual thin layers that were deposited on glass substrates. SCOUT allows the calculation of the spectral optical constants, refractive index (n) and extinction coefficient (к), besides the thickness of each individual layer. The used model enables to evaluate the complex dielectric function $\left(\tilde{\varepsilon}_{r}=\varepsilon_{1}+i \varepsilon_{2}\right)$ as frequency dependence, which is a result of a combination of several different types of oscillators, each with their own characteristic resonant frequency. So, the dielectric function $\tilde{\varepsilon}_{r}$ is considered as a sum of several contributions that describe the intraband and interband transitions, as shown in equation (2)

$\tilde{\varepsilon}_{r}=\tilde{\varepsilon}_{\text {back ground }}+\tilde{\varepsilon}_{\text {Drude }}+\sum \tilde{\varepsilon}_{\text {Lorentz }}+\tilde{\varepsilon}_{\text {OJL }}$

where $\tilde{\varepsilon}_{\text {back ground }}, \tilde{\varepsilon}_{\text {Drude }}, \tilde{\varepsilon}_{\text {Lorentz }}$ and $\tilde{\varepsilon}_{O J L}$ are background, Drude model for susceptibility of free carriers, harmonic oscillators for vibrational modes and OJL model for interband transitions, respectively (Bogaerts and Lampert, 1983)(Learys et al., 1998). Then, the complex refractive index ( $\tilde{n})$ can be calculated from the relation $\tilde{n}^{2}=(n+i \kappa)=\tilde{\varepsilon}_{r}$, where $\mathrm{n}$ is the refractive index and $\kappa$ is the extinction coefficient. Efficient selective absorber can be achieved, if it has a graded refractive index and extinction coefficient that decrease from back-reflector W-layer towards the antireflection layer. In ideal case, at the front of the antireflection layer, $\mathrm{n}$ and $\mathrm{k}$ should be 1 and 0, respectively. (Craighead et al., 1979) (Farooq and Lee, 2003).

Beginning with individual thin layers deposited on glass, the final tandem is obtained with a layer`s structure, thicknesses and simulated reflectance curve, as shown in Fig. 6.

(a)

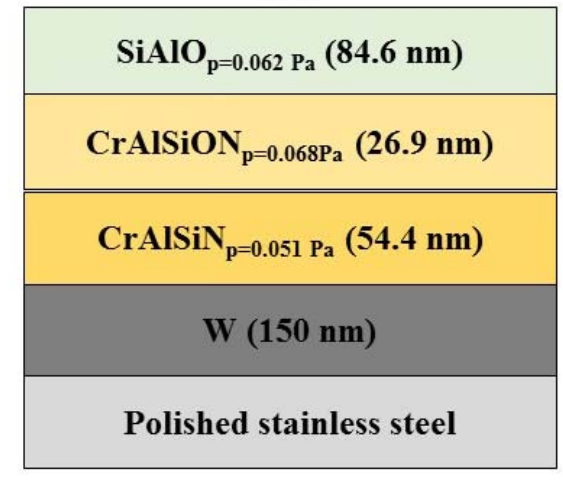

(b)

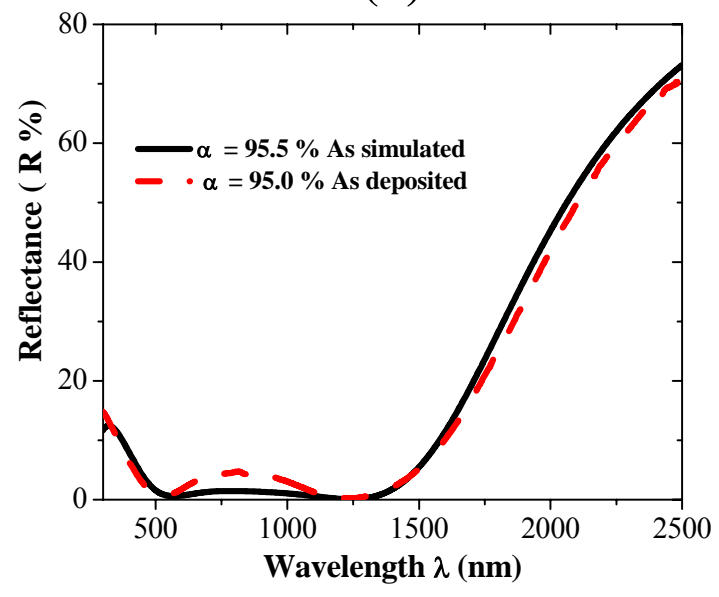

Fig. 6: (a) Schematic diagram of the simulated multilayer as obtained by SCOUT. (b) Simulated and experimental reflectance curves of the absorber design. 
As shown in Fig. 6a, the optical stack is composed of four layers, the first is a back-reflector tungsten layer, which is followed by two absorption layers based on $\mathrm{CrAlSiN}_{\mathrm{x}} / \mathrm{CrAlSiO}_{\mathrm{y}} \mathrm{N}_{\mathrm{x}}$ structure for phase interference. The final layer is an antireflection layer, that consists of $\mathrm{SiAlO}_{\mathrm{x}}$. The total simulated thickness of the whole multilayers absorber $\left(\mathrm{W} / \mathrm{CrAlSiN} \mathrm{x}_{\mathrm{x}} / \mathrm{CrAlSiO}_{\mathrm{y}} \mathrm{N}_{\mathrm{x}} / \mathrm{SiAlO}_{\mathrm{x}}\right.$ ) is $\sim 316 \mathrm{~nm}$. The experimental design shows good agreement with simulated one except small differences in the reflectance curves and absorption value, as shown in Fig. 6 b. This is due to the parameters of reactive sputtering deposition, where small variations can happen. The final design shows simultaneously high solar absorbance in average $\alpha=95.2 \%$ and low emissivity $\varepsilon=9.8 \%$ (at $400{ }^{\circ} \mathrm{C}$ ).

In accordance to that, Fig. 7 shows a cross-sectional SEM micrograph of the optical stack, deposited on silicon substrate. W layer shows a typical morphology of a columnar growth type, whereas the remaining layers reveal a featureless morphology that completely agrees with XRD analysis.

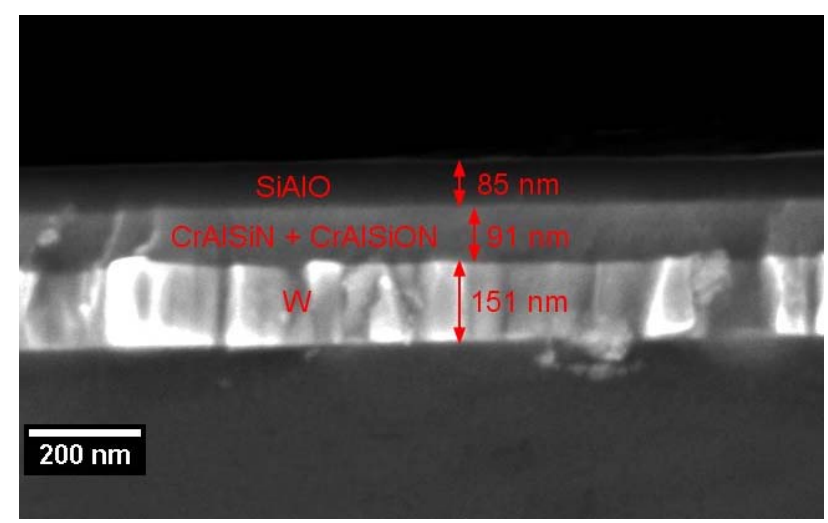

Fig. 7: Cross-sectional SEM micrograph of the optical stack, deposited on silicon substrate.

\subsection{Thermal stability}

For long lifetime, selective absorber stack should have good resistance of oxidation and it should be thermally stable. So, the optical stack was subjected to annealing tests in air at $400{ }^{\circ} \mathrm{C}$ and in vacuum at $600{ }^{\circ} \mathrm{C}$ for $650 \mathrm{~h}$. Then, the absorbance $(\alpha)$ was measured after each annealing step, and the emittance (ع) was calculated for each sample as deposited and for the last step of thermal annealing. Fig. 8a represents the reflectance curves of as deposited, after $350 \mathrm{~h}$ and after $650 \mathrm{~h}$ of air annealing. There is a very small shift in the step of the reflectance curve towards lower wavelength. As a result, the solar absorptance was improved a bit and the absorber stack shows good thermal stability. Fig. 8b shows the 
reflectance curves of as deposited, and vacuum annealed samples for $50 \mathrm{~h}, 350 \mathrm{~h}$ and $650 \mathrm{~h}$. Now, the shift towards lower wavelength was higher than air annealing case, especially after the first step of annealing $(50 \mathrm{~h})$. After further steps of vacuum annealing the changes were small, this demonstrates that the optical stack has very good thermal stability at this temperature. The shift caused a small decrease in solar absorptance (from $95.4 \%$ to $95.0 \%$ as shown in Figure 8b), but the emissivity improved (it decreased from $11.4 \%$ to $9.4 \%$ at $400{ }^{\circ} \mathrm{C}$ ). The change after first step can be related with oxidation of some $\mathrm{Si}$ atoms not yet completely oxidized and with desorption of some water vapor incorporated during deposition. Changes in additional steps can also be related with the diffusion of layer elements (such as the diffusion of Cr towards surface as will see in RBS analysis).

(a)

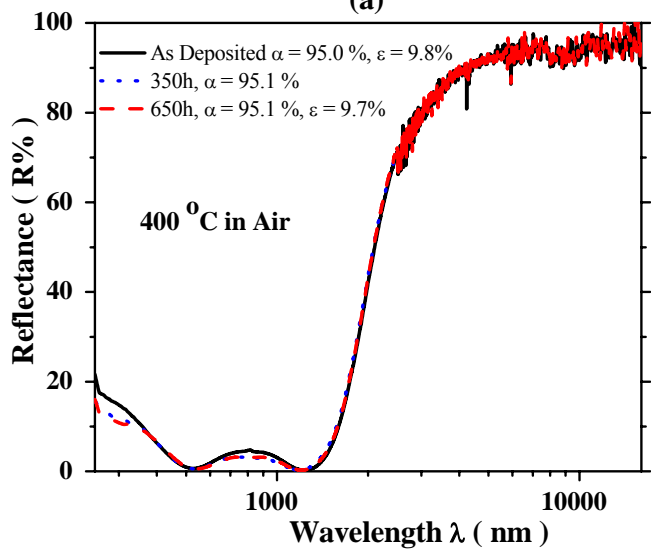

(b)

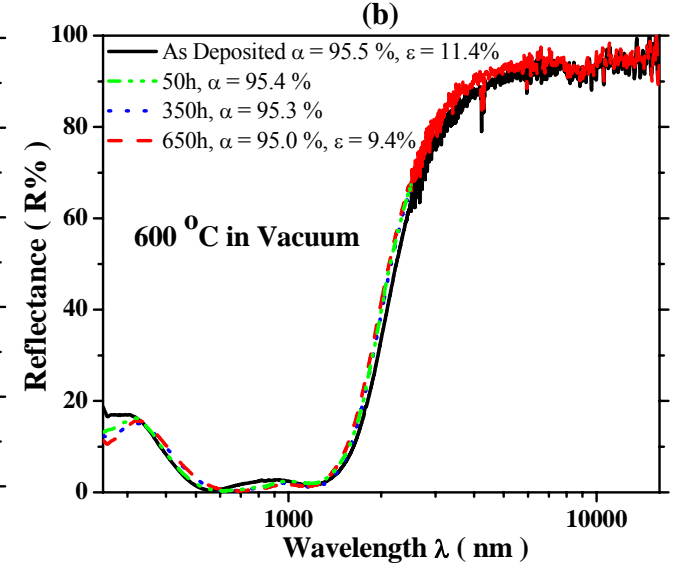

Fig. 8: Reflectance of as deposited optical stack and after (a) air thermal annealing at $400{ }^{\circ} \mathrm{C}$ (b) vacuum thermal annealing at $600{ }^{\circ} \mathrm{C}$, with measured value of thermal absorptance $(\alpha)$ and thermal emittance $(\varepsilon)$ (calculated for 400 $\left.{ }^{\circ} \mathrm{C}\right)$.

Elemental depth profiles of the absorber were studied by Rutherford back scattering (RBS). Fig. 9 shows RBS spectra of three optical stacks deposited in same run and subjected to different thermal load, namely as deposited, after air annealing at $400{ }^{\circ} \mathrm{C}$ for $650 \mathrm{~h}$ and after vacuum annealing at $600{ }^{\circ} \mathrm{C}$ for 650 h. Since the signals from the different elements can overlap, the composition should be determined from the front edges of the elements, which are indicated in the figure. The relative heights of those front edges are correlated with the relative concentrations of the different elements. The position of the different elements, if located at surface sample, are indicated in the graph. It is difficult to distinguish between silicon and aluminum because of the small difference of their atomic mass. However, the analysis shows a small difference between as deposited and annealed samples. After air annealing a small change is seen in the stainless steel substrate, which was not clearly identified. After vacuum annealing at $600{ }^{\circ} \mathrm{C}$, it can be seen changes of $\mathrm{W}$ and $\mathrm{Cr}$ depth profiles, which are in accordance with the diffusion of small amount of tungsten towards the stainless steel substrate and chromium, mainly from $\mathrm{CrAlSiO}_{\mathrm{y}} \mathrm{N}_{\mathrm{x}}$ layer, towards the 
surface. The general evaluation shows that no other significant changes occurred after annealing in vacuum and air. So, a diffusion barrier layer should be added between stainless steel substrate and tungsten layer to improve barrier diffusion between these layers.

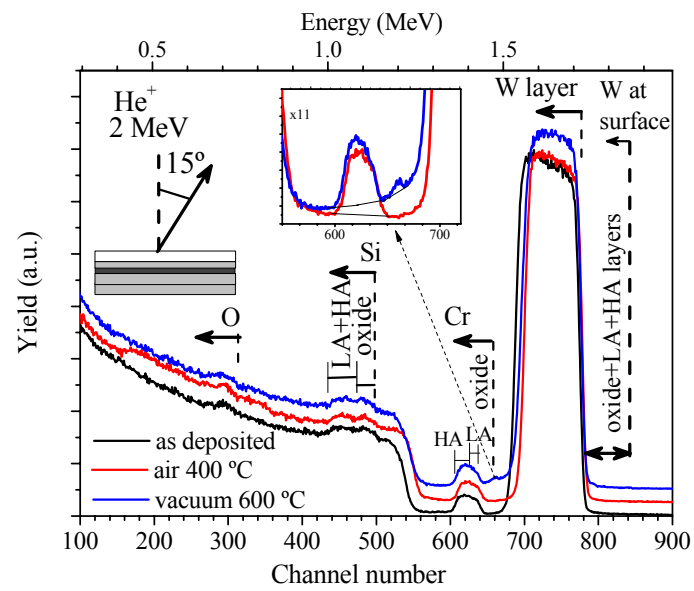

Fig. 9: RBS spectra of the as deposited stack, after air annealing at $400{ }^{\circ} \mathrm{C}$ and vacuum annealing at $600{ }^{\circ} \mathrm{C}$, both for $650 \mathrm{~h}$.

For more details about the structural changes in the optical stacks after annealing, samples were analyzed by XRD. Fig. 10 represents the diffractograms of samples before and after vacuum and air annealing at $600{ }^{\circ} \mathrm{C}$ and $400{ }^{\circ} \mathrm{C}$, respectively. As it is shown in the figure, there are no significant changes after the annealing, except small differences in the stainless steel peaks and the intensity of $\mathrm{W}$ peaks. This confirms that the stack showed a good resistance against oxidation and good thermal stability.

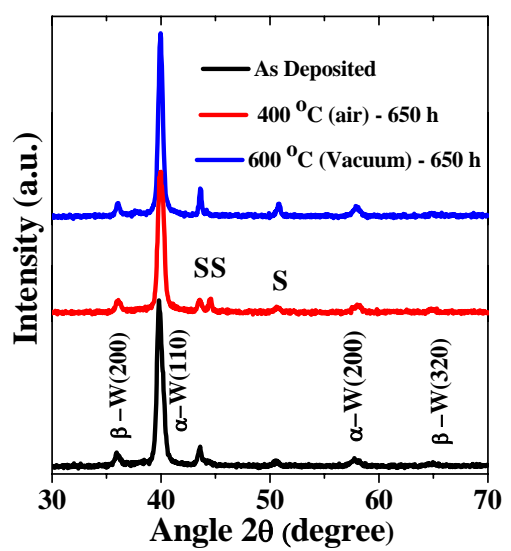

Fig. 10: X-ray diffraction of as deposited thermal absorber and after thermal annealing. (the peaks referenced by $S$ correspond to stainless steel as recorded by the previous study (Dias et al., 2017) ).

\section{Conclusions}


A design of selective solar absorbance for high temperature applications was fabricated by magnetron spattering method. It is a multilayer that consists in a structure of four layers $\left(\mathrm{W} / \mathrm{CrAlSiN} \mathrm{x}_{\mathrm{x}}\right.$ $/ \mathrm{CrAlSiO}_{\mathrm{y}} \mathrm{N}_{\mathrm{x}} / \mathrm{SiAlO}_{\mathrm{x}}$ ), as back reflector/ high absorber/ low absorber/antireflector layers, respectively. The total thickness of the stack is $\sim 327 \mathrm{~nm}$ as measured by SEM. The structure was simulated by the SCOUT software. Experimental design shows simultaneously high average solar absorbance $\alpha=95.2 \%$ and low emissivity $\varepsilon=9.8 \%$ (at $400{ }^{\circ} \mathrm{C}$ ) together with high thermal stability at $400{ }^{\circ} \mathrm{C}$, in air and at 600 ${ }^{\circ} \mathrm{C}$, in vacuum, for $650 \mathrm{~h}$. After the first step of thermal annealing in vacuum at $600{ }^{\circ} \mathrm{C}$, the reflectance curve of the stack shifted towards lower wavelength, which caused a decrement in the value of solar absorbance. However, after further steps of annealing, no significant changes were seen. In most cases, thermal emissivity improved a bit or stayed constant, which implies that the $\mathrm{W}$ back reflector layer maintained its reflectivity meaning it is well protected by the outermost layers. On other hand, it was recorded by RBS analysis that a small amount of W diffused toward stainless steel substrate. This diffusion can be easily controlled by adding a diffusion barrier layer between stainless steel substrate and tungsten layer. Finally, the $\mathrm{CrAlSiN}_{\mathrm{x}} / \mathrm{CrAlSiO}_{\mathrm{y}} \mathrm{N}_{\mathrm{x}}$ and $\mathrm{SiAlO}_{\mathrm{x}}$ layers show a featureless morphology, which is in accordance with the XRD amorphous like structure. The $\mathrm{W}$ layer showed a combination of both $\alpha$ - and $\beta$ - phase of growth, but the $\alpha$ - phase is dominant and it is polycrystalline with (110) orientation.

\section{ACKNOWLEDGMENTS}

The authors acknowledge the support of FCT in the framework of the Strategic Funding UID/FIS/04650/2013 and the financial support of FCT, POCI and PORL operational programs through the project POCI-01-0145FEDER-016907 (PTDC/CTM-ENE/2882/2014), co-financed by European community fund FEDER.

\section{References}

Al-Rjoub, A., Costa, P., Rebouta, L., Cerqueira, M.F., Alpuim, P., Barradas, N.P., Alves, E., 2017. Characterization of magnetron sputtered sub-stoichiometric CrAlSiNx and CrAlSiOyNx coatings. Surf. Coat. Technol. doi:10.1016/j.surfcoat.2017.08.038

Barradas, N.P., Jeynes, C., 2008. Advanced physics and algorithms in the IBA DataFurnace. Nucl. Instruments Methods Phys. Res. Sect. B Beam Interact. with Mater. Atoms 266, 1875-1879. doi:10.1016/j.nimb.2007.10.044

Barshilia, H.C., Selvakumar, N., Rajam, K.S., 2007. Thermal stability of TiAlN/TiAlON/Si 3 $\mathrm{N} 4 \mathrm{TiAlN} / \mathrm{TiAlO} \mathrm{N} / \mathrm{Si} 3 \mathrm{~N} 4$ tandem absorbers prepared by reactive direct. jounal Vac. Sci. Technol. 383, 2699425.

Bogaerts, W., Lampert, C., 1983. energy conversion. Mater. Sci. 18, 2847-2875.

Craighead, H.G., Bartynski, R., A, R.B., 1979. Metal/Insulator composite selective absorbers 1, $105-124$.

Dias, D., Rebouta, L., Costa, P., Al-rjoub, A., Benelmeki, M., Tavares, C.J., Barradas, N.P., Alves, E., Santilli, P., Pischow, K., 2017. Optical and structural analysis of solar selective absorbing coatings based on A1SiO x : W cermets. Sol. Energy 150, 335-344. doi:10.1016/j.solener.2017.04.055 
Farooq, M., Lee, Z.H., 2003. Computations of the optical properties of metal / insulatorcomposites for solar selective absorbers. Renew. energy 28, 1421-1431. doi:10.1016/S0960-1481(02)00033-2

Fernández-García, A., Zarza, E., Valenzuela, L., Pérez, M., 2010. Parabolic-trough solar collectors and their applications. Renew. Sustain. Energy Rev. 14, 1695-1721. doi:10.1016/j.rser.2010.03.012

Kennedy, C.E., 2002. Review of Mid- to High- Temperature Solar Selective Absorber Materials. NREL/TP-520-31267, Natl. Renew. Energy Lab. Goledn, CO.

Learys, S.K.O., Lim, R.J.K., Leary, S.K.O., 1998. The relationship between the distribution of electronic states and the optical absorption spectrum of an amorphous semiconductor : An empirical analysis The relationship between the distribution of electronic states and the optical absorption spectrum of. Appl. Phys. 3334. doi:10.1063/1.365643

Nuru, Z.Y., Arendse, C.J., Nemutudi, R., Nemraoui, O., Maaza, M., 2012. Pt - Al 2 O 3 nanocoatings for high temperature concentrated solar thermal power applications. Phys. B Phys. Condens. Matter 407, 1634-1637. doi:10.1016/j.physb.2011.09.104

Odeh, S.D., Morrison, G.L., Behnia, M., 1998. Modelling of parabolic trough direct steam generation solar collectors 62, 395-406.

Rebouta, L., Sousa, A., Andritschky, M., Cerqueira, F., Tavares, C.J., Santilli, P., Pischow, K., 2015. Solar selective absorbing coatings based on AlSiN/AlSiON/AlSiOy layers. Appl. Surf. Sci. 356, 203-212. doi:10.1016/j.apsusc.2015.07.193

Selvakumar, N., Barshilia, H.C., 2012. Review of physical vapor deposited (PVD) spectrally selective coatings for mid- and high-temperature solar thermal applications. Sol. Energy Mater. Sol. Cells 98, 1-23. doi:10.1016/j.solmat.2011.10.028

Shen, Y.G., Mai, Y.W., 2006. Influences of oxygen on the formation and stability of A15 b -W thin films. Mater. Sci. Eng. A 284, 176-183.

Sibin, K.P., John, S., Barshilia, H.C., 2015. Control of thermal emittance of stainless steel using sputtered tungsten thin films for solar thermal power applications. Sol. Energy Mater. Sol. Cells 133, 1-7. doi:10.1016/j.solmat.2014.11.002

Theiss, W., 2002. SCOUT Thin Film Analysis Software Handbook.

Wang, X., Gao, J., Hu, H., Zhang, H., Liang, L., Javaid, K., 2017. Nano Energy Hightemperature tolerance in WTi-Al 2 O 3 cermet-based solar selective absorbing coatings with low thermal emissivity. Nano Energy 37, 232-241. doi:10.1016/j.nanoen.2017.05.036

Ward, J., 1997. Modelling, optimisation and performance evaluation of a parabolic trough solar collector steam generation system. Sol. Energy 60, 49-59.

Yin, Y., Collins, R.E., 1995. Optimization and analysis of solar selective surfaces with continuous and multilayer profiles. J. Appl. Physiscs. doi:10.1063/1.359124

Zhang, Q., Mills, D.R., Zhang, Q., Mills, D.R., 1992. Very low-emittance solar selective surfaces using new film structures Very low-emittance solar selective surfaces using new film structures. J. Appl. Phys. 3013. doi:10.1063/1.351510

Zhang, Q., Yin, Y., Mills, D.R., 2006. High efficiency Mo-AI203 cermet selective surfaces for high-temperature application. Sol. Energy Mater. Sol. Cells 40, 43-53.

Zou, C., Xie, W., Shao, L., 2016. Functional multi-layer solar spectral selective absorbing coatings of $\mathrm{AlCrSiN} / \mathrm{AlCrSiON} / \mathrm{AlCrO}$ for high temperature applications. Sol. Energy Mater. Sol. Cells 153, 9-17. doi:10.1016/j.solmat.2016.04.007 